\title{
E- and P-Selectin: Differences, Similarities and Implications for the Design of P-Selectin Antagonists
}

\author{
Florian P. C. Binder $\S^{\star}$ and Beat Ernst \\ §SCS Metrohm Prize for best oral presentation
}

\begin{abstract}
Selectins form a family of $\mathrm{Ca}^{2+}$-dependent carbohydrate binding proteins that mediate the initial step of leukocyte recruitment in the inflammatory process. Blocking of selectins is therefore considered a promising therapeutic approach to treat acute and chronic inflammatory diseases which are caused by excessive extravasation of leukocytes. This mini-review highlights the major structural differences between $\mathrm{E}$ - and P-selectin and summarizes the resulting strategies for the design of selectin antagonists.
\end{abstract}

Keywords: Antagonist · Glycomimetics · PSGL-1 · Selectin · Sialyl Lewis ${ }^{\mathrm{X}}$

\section{Background}

The selectins, namely E-, P-, and L-selectin, form a family of $\mathrm{Ca}^{2+}$-dependent lectins. Upon an inflammatory stimulus, E- and P-selectin are upregulated on endothelial cells (E-selectin, P-selectin) and platelets (P-selectin). They mediate the rolling of leukocytes on the endothelial surface, which is followed by firm adhesion via the interaction of integrins with members of the super IgG family and transmigration to the site of inflammation. ${ }^{[1]}$ This process, forming a vital defense mechanism in the event of injuries or infections, can turn deleterious in numerous diseases with an inflammatory component like stroke, reperfusion injury, psoriasis or rheumatoid arthritis. ${ }^{[2]}$ Furthermore, selectins are involved in tumor metastasis. ${ }^{[3]}$ Therefore, blocking the interaction of selectins with their physiological ligands has been recognized as a promising therapeutic approach for the therapy of these diseases. Consequently, various concepts have been applied to disrupt the selectinmediated cell-cell interaction, either by antagonizing the receptor, by modulating selectin expression, or by cleaving selectin ligands. ${ }^{[4]}$ This mini-review gives an overview on E- and P-selectin antagonists and elucidates how their design is guided by differences and similarities between $\mathrm{E}$ - and P-selectin.

\section{E- and P-Selectin: Differences and Similarities}

The tetrasaccharide sialyl Lewis ${ }^{\mathrm{x}}\left(\mathrm{sLe}^{\mathrm{x}}\right.$, Fig. 1) was identified as the minimal carbohydrate binding epitope recognized by all three selectins. ${ }^{[8]}$ The carbohydrate recognition domain (CRD) of $\mathrm{E}$ - and $\mathrm{P}$-selectin, which is characterized by a $\mathrm{Ca}^{2+}$ ion essential for $\mathrm{SLe}^{\mathrm{x}}$ binding, is almost identical. ${ }^{[9,10]}$ Consequently, similarconformationsof $\mathrm{SLe}^{\mathrm{x}}$ bound to P- and E-selectin were found. $[10,11]$ Besides the CRD for $\mathrm{SLe}^{\mathrm{x}}$, P-selectin offers a second, structurally and operationally distinct binding site not present on E-selectin. ${ }^{[12]}$ This second site is rich in positively charged amino acid side chains and therefore allows binding of a broad range of negatively charged biopolymers (section 4). The natural ligand of P-selec-

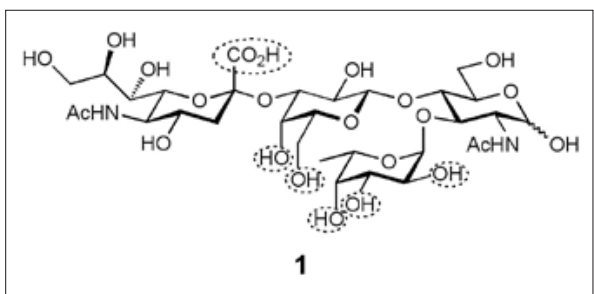

Fig. 1. The tetrasaccharide sialyl Lewis ${ }^{\times}(\mathbf{1})$ and its pharmacophoric groups: hydroxyl groups in 2-, 3-, and 4- position of fucose, ${ }^{[5,6]}$ hydroxyl groups in 4- and 6- position of galactose $\mathrm{e}^{[7]}$ and the carboxylic acid residue of sialic acid. ${ }^{[5]}$

tin, P-selectin glycoprotein ligand 1 (PSGL-1), binds to both sites, the CRD and the polyanion binding site, simultaneously.[10] Its binding epitopes include $\mathrm{sLe}^{\mathrm{x}}$, which is essential for recognition, ${ }^{[13]}$ and three sulfated tyrosines (Tyr 46, 48, 51), which are vital for high binding affinity (Fig. 2). ${ }^{[10,14,15]}$ When these two binding epitopes are combined, a synergistic effect ${ }^{[12]}$ leads to an approximately 10'000-fold improved binding of PSGL-1 compared to sLe ${ }^{\mathrm{x}}$.[11,16]

The existence of a second binding site on P-selectin obviously has major implica-
${ }^{\star}$ Correspondence: Dipl. Chem. F. P. C. Binder Institute of Pharmaceutical Chemistry University of Basel

Klingelbergstrasse 50

$\mathrm{CH}-4056$ Basel

Tel.: +41612671556

Fax: + 41612671552

E-mail: florian.binder@unibas.ch

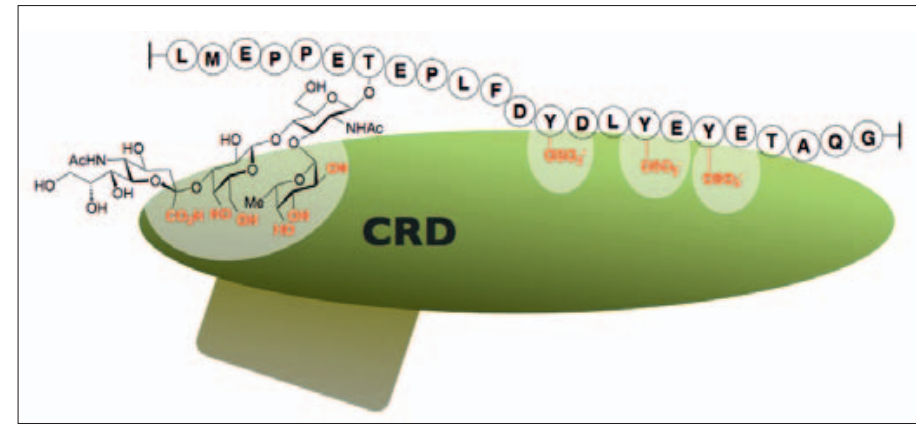

Fig. 2. Interaction between $\mathrm{P}$-selectin and PSGL-1. 
tions on the design of P-selectin antagonists. According to the addressed binding sites, P-selectin antagonists are divided into three groups: mimetics of $\mathrm{sLe}^{\mathrm{x}}$ (section 3 ), polyanions (section 4), and mimetics of PSGL-1 (section 5).

\section{Mimetics of $s L e^{x}$}

Since $\mathrm{sLe}^{\mathrm{x}}$ is the common binding epitope recognized by all three selectins, it has served as starting point for numerous drug discovery programs. The tetrasaccharide itself suffers from the typical downsides of carbohydrates, which are the poor pharmacokinetic and pharmacodynamic properties as well as complex synthesis, and therefore ultimately failed as drug candidate. ${ }^{[17]}$ In consequence, efforts were primarily directed to reduce the carbohydrate character while enhancing affinity and conserving the pharmacophore (Fig. 1).

The search for high affinity-antagonists followed two major strategies. In a first approach, the carbohydrate moieties were systematically replaced with mimetics containing the relevant pharmacophoric groups. In a second approach, antagonists were rationally designed based on the pharmacophore of sLe ${ }^{\mathrm{x}}$. Furthermore, database screening with the 3D pharmacophore of $\mathrm{sLe}^{\mathrm{x}}$ and high throughput screening yielded additional leads. Since the resulting antagonists up to 2002 are covered by several excellent reviews, ${ }^{[17,18]}$ only two representative examples of that period are discussed here. Following the first strategy, a group at Ciba and later at Novartis replaced the sialic acid moiety of $\operatorname{sLe}^{\mathrm{x}}$ by $S$-cyclohexyl lactic acid and the $N$-acetyl glucosamine unit with $R, R$ 1,2-cyclohexanediol. The resulting lead CGP69669A (2) ${ }^{[19]}$ was further developed by Glycomimetics Inc. to the pan-selectin antagonist GMI-1070 (3) ${ }^{[20]}$ which is now in Phase II clinical trials for the treatment of sickle cell crisis (Fig. 3). Kogan et al. applied the second strategy to design a series of biphenyl-based inhibitors mimicking the hydroxyl groups of L-fucose with D-mannose and the carboxylic acid residue of sialic acid.[21] TBC265 (4, Fig. 4) shows affinity for E-, P-, and L-selectin. Its dimer TBC1269 (5) ${ }^{[22]}$ is currently in Phase II clinical trials for treatment of asthma and psoriasis.

Recently published selectin antagonists exemplify a clear trend to compounds lacking any carbohydrate moiety. Kranich et al. used TBC1269 (5) as template for the rational design of a series of nonglycosidic, nonpeptidic, polyphenolic pan-selectin antagonists, e.g. 6 in Fig. 5. ${ }^{[23]}$ For the best representatives, low micromolar affinities in a static cell free assay and significant inhibition of HL-60 cell attachment to se-

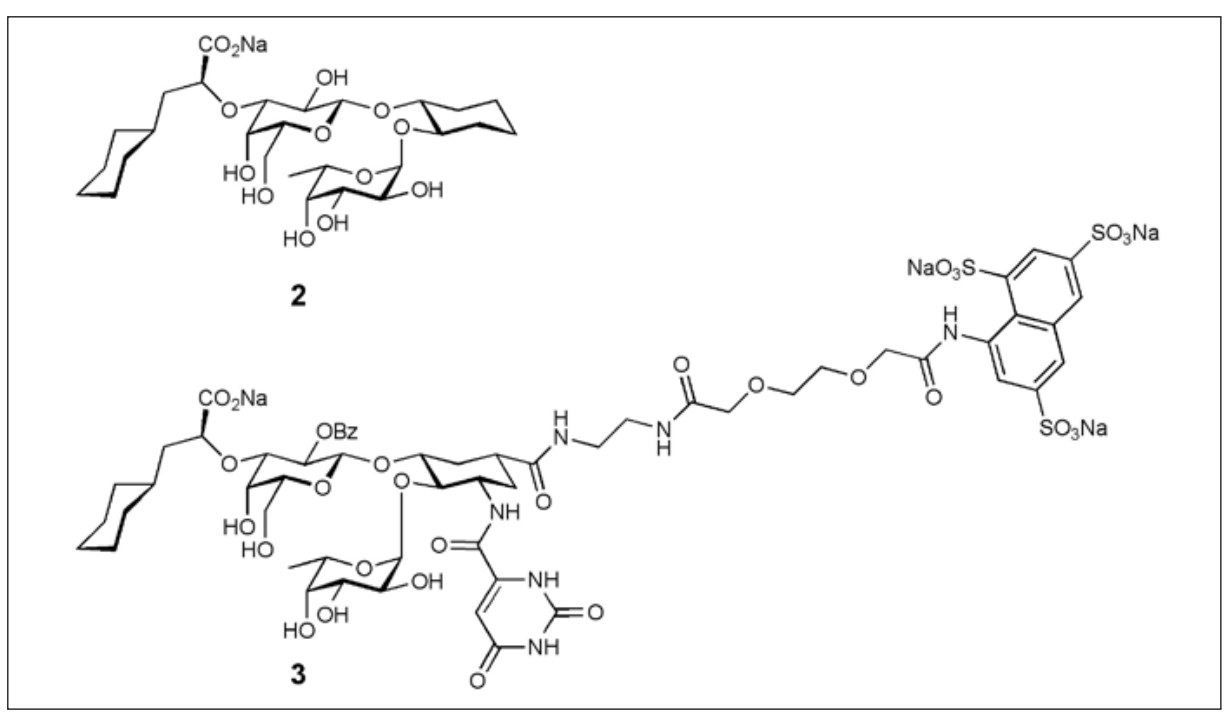

Fig. 3. E-selectin antagonist CGP69669A (2) and pan-selectin antagonist GMI-1070 (3).

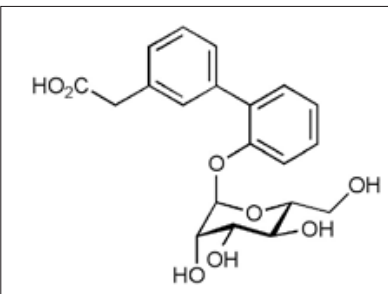

4

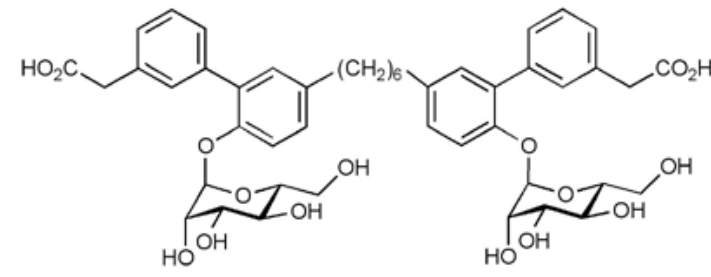

5

Fig. 4. TBC265 (4) and its dimer TBC1269 (5).

lectins under flow conditions are reported. Although initially designed to mimic sLe ${ }^{\mathrm{x}}$, the authors also consider the possibility of alternative binding modes. Based on a pharmacophore model originally developed by the Kondo group, [24] Ulbrich et al. recently developed pan-selectin inhibitors with two carboxylates and a hydrophobic tail (e.g. 7, Fig. 5). ${ }^{[25]}$ They propose that one carboxylate coordinates to $\mathrm{Ca}^{2+}$ and the second one forms a salt bridge to Arg97 of E-selectin or Lys99 of P-selectin. The long alkyl chains are considered to interact with hydrophobic regions of the selectins. Although the authors claim the absence of micelles at concentrations equal to the $\mathrm{IC}_{50}$, the antagonists obviously resemble detergents. Therefore, multivalency due to micelle formation or simply unspecific lipophilic interactions might be the reason for their affinity. This hypothesis is supported by the fact that total loss of affinity was reported for compounds lacking the hydrophobic tail. The groups of Kaila and Girard independently reported on quinic acid derivatives mimicking $\mathrm{sLe}^{\mathrm{x}}$, e.g. $\mathbf{8}^{[26]}$ and 9[27] (Fig. 5). Their hypothesis that quinic acid mimics fucose and coordinates to $\mathrm{Ca}^{2+}$ was confirmed by a crystal structure of quinic acid in complex with E-selectin. ${ }^{[26]}$ Kaila and coworkers found only low affinities for their compounds in a surface plasmon resonance assay. However, two of their compounds efficiently blocked leukocyte rolling in vivo (e.g. 8, Fig. 5). Girard et al. reported $\mathrm{IC}_{50}$ values in the millimolar range in a cell-based competitive binding assay for their P- and E-selectin antagonists (e.g. 9, Fig. 5).[27] Researchers at Wyeth identified quinoline salicylic acids as promising P-selectin antagonists via high-throughput screening. ${ }^{[28]}$ The lead compound PSI-697 (10) ${ }^{[29]}$ is currently in Phase I clinical trials and the follow-up PSI-421 (11) ${ }^{[30]}$ has reached the predevelopment stage. Finally, Schön et al. reported on the macrolide efomycine M (12) as a potent selectin antagonist mimicking sLe $^{\mathrm{x}}{ }^{[31]}$ Though the exact binding mode is still being discussed controversially, ${ }^{[32]}$ it is interesting to note that efomycine $\mathrm{M}$ significantly reduced leukocyte rolling in vivo and alleviated cutaneous inflammation in two mouse models of psoriasis.

\section{Polyanions}

Numerous polyanions like sulfatides, ${ }^{[33]}$ heparin, ${ }^{[34]}$ lipopolysaccharides (LPS), ${ }^{[35]}$ fucoidin, sulfated dextran, ${ }^{[36]}$ chondroitin sulfate, ${ }^{[37]}$ dermatan sulfate, ${ }^{[38]}$ and sulfated hyaluronic acid ${ }^{[39]}$ have been reported to exhibit $\mathrm{P}$-selectin antagonism. The broad range of charged compounds lacking the carbohydrate epitope suggests 


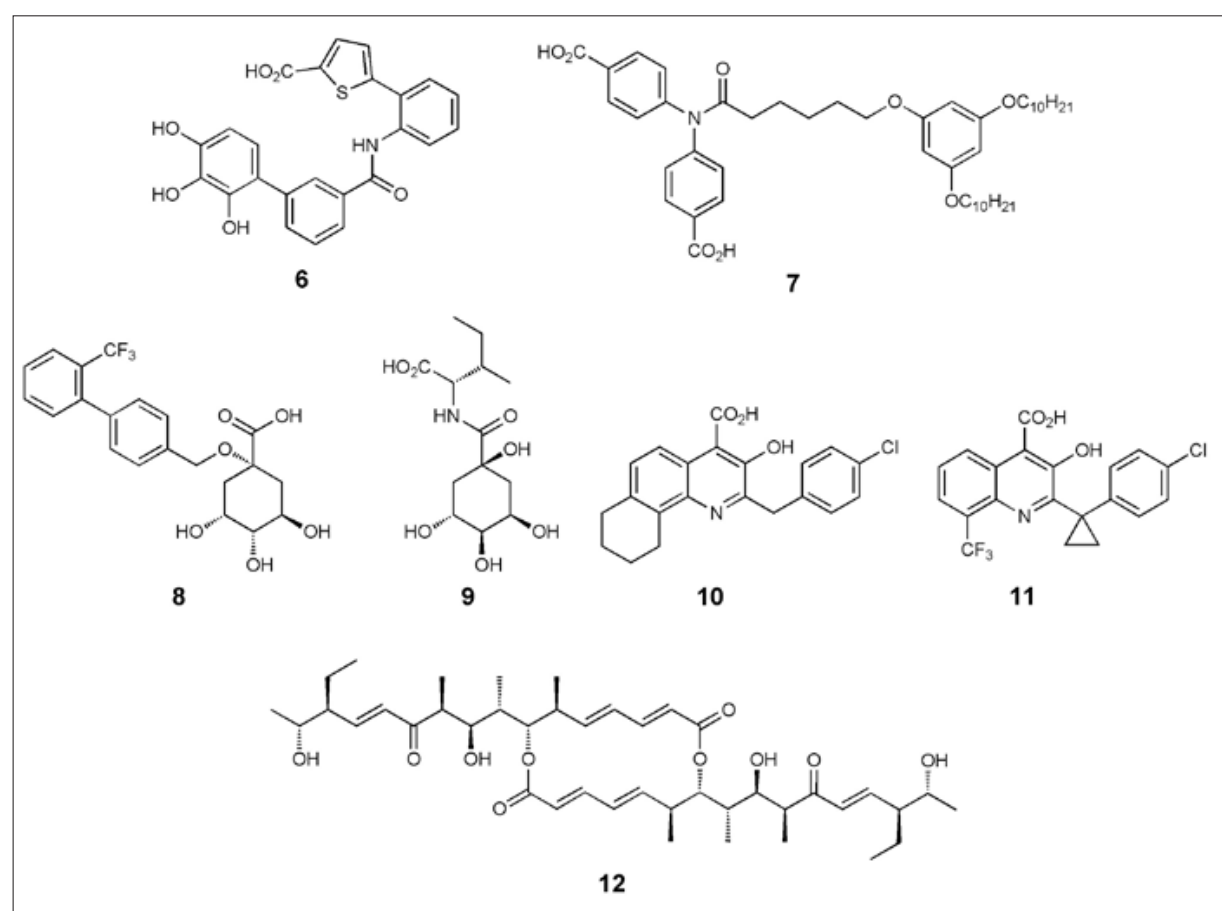

Fig. 5. Representative examples of recently published selectin antagonists.

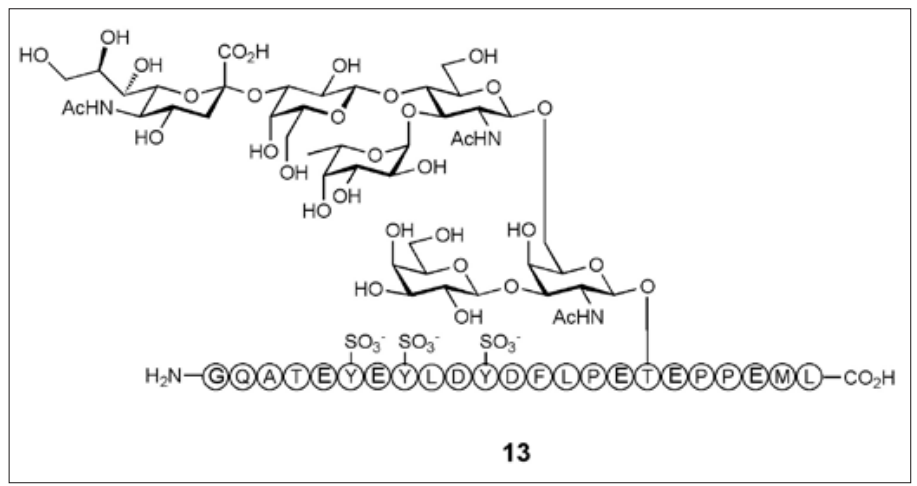

Fig. 6. PSGL-1 fragment GSP-6 (13) ${ }^{[46]}$

unspecific binding via charge-charge interactions to the numerous positively charged amino acid side chains in areas adjacent to the CRD. $\mathrm{Ca}^{2+}$-independent binding of LPS, heparin, and sulfatides supports this hypothesis. ${ }^{[34,35,40]}$ Nevertheless, the therapeutic effect of heparin was tested in several clinical trials in selectin associated inflammatory diseases and cancer. ${ }^{[41]}$ Even more, the suppression of P-selectin function by heparin could be correlated to its antimetastatic activity in vivo. ${ }^{[42]}$ Current efforts are directed to reduce the anticoagulant effect of heparin, while retaining its anti-inflammatory and antimetastatic potential. Besides natural polyanions, dendritic polyglycerol sulfates ${ }^{[43]}$ and functionalized nanoparticles ${ }^{[44]}$ were developed to block P-selectin via electrostatic interactions.

\section{PSGL-1 and Mimetics Thereof}

PSGL-1 binds to P-selectin with nanomolar affinity $(320 \mathrm{nM})^{[16]}$ and conse- quently is a promising lead for high affinity P-selectin antagonists. Several groups have been working on chemoenzymatic and chemical routes to synthesize the N-terminal recognition domain of PSGL-1. ${ }^{[45,46]}$ These truncated glycosulfopeptides, e.g. GSP-6 (13, Fig. 6), comprise sulfated tyrosines and a core 2-based $O$-glycan with $\mathrm{sLe}^{\mathrm{x}}$ and exhibit binding affinities similar to PSGL-1. ${ }^{[10,46]}$ Furthermore, a recombinant soluble form of PSGL-1, rPSGL-Ig, was developed and is currently in clinical trials.

Besides these analogues of PSGL-1, mimetics have been designed that combine a carbohydrate and an anionic part, and potentially target both binding sites of P-selectin. GMI-1070 (Fig. 3) for instance comprises a $\mathrm{sLe}^{\mathrm{x}}$ mimic combined with a naphtyl sulfonic acid moiety to support binding to all three selectins. Furthermore, to directly mimic PSGL-1, polymers that combine $\mathrm{sLe}^{\mathrm{x}}$ and tyrosine sulfate were developed. These polymers revealed synergistic effects compared to polymers containing $\mathrm{sLe}^{\mathrm{x}}$ tetrasaccharides or tyrosine sulfates alone. ${ }^{[47]}$ Smaller fragments mimicking the binding epitopes on PSGL-1 have also been assembled successfully on nanoparticles. ${ }^{[44,48]}$ Since monovalent fragments show no significant inhibitory effect on P-selectin binding, the affinity of these nanoparticles was suggested to result from multivalency.

\section{Conclusion and Outlook}

E- and P-selectin share a high degree of similarity in their CRDs. Numerous antagonists that target these binding sites by mimicking $\mathrm{sLe}^{\mathrm{x}}$ have been developed, and the successful performance of several of these antagonists in preclinical and clinical tests convincingly prove that small molecules are indeed suited as selectin antagonists. Finally, small molecules occupying both binding sites of P-selectin potentially offer increased affinity and selectivity and might fill an important gap in the therapy with selectin antagonists.

Received: January 14, 2011

[1] G. S. Kansas, Blood 1996, 88, 3259; A. Varki, Proc. Natl. Acad. Sci. USA 1994, 91, 7390.

[2] S. A. Mousa, D. A. Cheresh, Drug Discov. Today 1997, 2, 187.

[3] S. Chen, M. Fukuda, Methods in Enzymol. 2006, 371; H. Laubli, L. Borsig, Semin. Cancer Biol. 2010, 20, 169.

[4] P. W. Bedard, N. Kaila, Expert Opin. Ther. Pat. 2010, 20, 781 .

[5] B. K. Brandley, M. Kiso, S. Abbas, P. Nikrad, O. Srivasatava, C. Foxall, Y. Oda, A. Hasegawa, Glycobiology 1993, 3, 633.

[6] J. Y. Ramphal, Z. L. Zheng, C. Perez, L. E. Walker, S. A. Defrees, F. C. A. Gaeta, J. Med. Chem. 1994, 37, 3459.

[7] W. Stahl, U. Sprengard, G. Kretzschmar, H. Kunz, Angew. Chem. Int. Ed. Engl. 1994, 33, 2096.

[8] C. Foxall, S. R. Watson, D. Dowbenko, C. Fennie, L. A. Lasky, M. Kiso, A. Hasegawa, D. Asa, B. K. Brandley, J. Cell Biol. 1992, 117, 895.

[9] D. V. Erbe, S. R. Watson, L. G. Presta, B. A. Wolitzky, C. Foxall, B. K. Brandley, L. A. Lasky, J. Cell Biol. 1993, 120, 1227.

[10] W. S. Somers, J. Tang, G. D. Shaw, R. T. Camphausen, Cell 2000, 103, 467.

[11] L. Poppe, G. S. Brown, J. S. Philo, P. Nikrad, B. H. Shah, J. Am. Chem. Soc. 1997, 119, 1727.

[12] C. Galustian, R. A. Childs, M. Stoll, H. Ishida, M. Kiso, T. Feizi, Immunology 2002, 105, 350.

[13] D. Sako, X. J. Chang, K. M. Barone, G. Vachino, H. M. White, G. Shaw, G. M. Veldman, K. M. Bean, T. J. Ahern, B. Furie, D. A. Cumming, G. R. Larsen, Cell 1993, 75, 1179; K. L. Moore, N. L. Stults, S. Diaz, D. F. Smith, R. D. Cummings, A. Varki, R. P. McEver, J. Cell Biol. 1992, 118, 445.

[14] P. P. Wilkins, K. L. Moore, R. P. McEver, R. D. Cummings, J. Biol. Chem. 1995, 270, 22677.

[15] D. Sako, K. M. Comess, K. M. Barone, R. T Camphausen, D. A. Cumming, G. D. Shaw, Cell 1995, 83, 323 .

[16] P. Mehta, R. D. Cummings, R. P. McEver, J. Biol. Chem. 1998, 273, 32506.

[17] N. Kaila, B. E. Thomas, Expert Opin. Ther. Pat. 2003, 13, 305. 
[18] B. Ernst, J. L. Magnani, Nat. Rev. Drug Discov 2009, 8, 661; B. Ernst, H. C. Kolb, O. Schwardt, in 'The Organic Chemistry of Sugars', Eds. D. E. Levy, P. Fügedi, CRC Press, Boca Raton, 2006, p. 803; E. E. Simanek, G. J. McGarvey, J. A. Jablonowski, C. H. Wong, Chem. Rev. 1998, 98, 833.

[19] K. E. Norman, G. P. Anderson, H. C. Kolb, K. Ley, B. Ernst, Blood 1998, 91, 475.

[20] J. S. Chang, J. T. Patton, A. Sarkar, B. Ernst, J. L. Magnani, P. S. Frenette, Blood 2010, 116, 1779.

[21] T. P. Kogan, B. Dupre, K. M. Keller, I. L. Scott, H. Bui, R. V. Market, P. J. Beck, J. A. Voytus, B. M. Revelle, D. Scott, J. Med. Chem. 1995, 38, 4976.

[22] T. P. Kogan, B. Dupre, H. Bui, K. L. McAbee, J. M. Kassir, I. L. Scott, X. Hu, P. Vanderslice, P. J. Beck, R. A. F. Dixon, J. Med. Chem. 1998 41, 1099.

[23] R. Kranich, A. S. Busemann, D. Bock, S. Schroeter-Maas, D. Beyer, B. Heinemann, M. Meyer, K. Schierhorn, R. Zahlten, G. Wolff, E M. Aydt, J. Med. Chem. 2007, 50, 1101.

[24] Y. Hiramatsu, T. Tsukida, Y. Nakai, Y. Inoue, H. Kondo, J. Med. Chem. 2000, 43, 1476

[25] H. K. Ulbrich, A. Luxenburger, P. Prech, E. E. Eriksson, O. Soehnlein, P. Rotzius, L. Lindbom, G. Dannhardt, J. Med. Chem. 2006, 49, 5988

[26] N. Kaila, W. S. Somers, B. E. Thomas, P. Thakker, K. Janz, S. DeBernardo, S. Tam, W. J. Moore, R. Y. Yang, W. Wrona, P. W. Bedard, D. Crommie, J. C. Keith, D. H. H. Tsao, J. C. Alvarez, H. Ni, E. Marchese, J. T. Patton, J. L. Magnani, R. T. Camphausen, J. Med. Chem 2005, 48, 4346.

[27] C. Girard, J. Dourlat, A. Savarin, C. Surcin, S Leue, V. Escriou, C. Largeau, J. Herscovici, D. Scherman, Bioorg. Med. Chem. Lett. 2005, 15 3224.

[28] N. Kaila, K. Janz, S. DeBernardo, P. W. Bedard, R. T. Camphausen, S. Tam, D. H. H. Tsao, J. C. Keith, C. Nickerson-Nutter, A. Shilling, R Young-Sciame, Q. Wang, J. Med. Chem. 2007, $50,21$.
[29] N. Kaila, K. Janz, A. Huang, A. Moretto, S. DeBernardo, P. W. Bedard, S. Tam, V. Clerin, J. C. Keith, D. H. H. Tsao, N. Sushkova, G. D. Shaw, R. T. Camphausen, R. G. Schaub, Q. Wang, J. Med. Chem. 2007, 50, 40.

[30] A. Huang, A. Moretto, K. Janz, M. Lowe, P. W. Bedard, S. Tam, L. Di, V. Clerin, N. Sushkova, B. Tchernychev, D. H. H. Tsao, J. C. Keith, G. D. Shaw, R. G. Schaub, Q. Wang, N. Kaila, J. Med. Chem. 2010, 53, 6003.

[31] M. P. Schön, T. Krahn, M. Schön, M. L. Rodriguez, H. Antonicek, J. E. Schultz, R. J. Ludwig, T. M. Zollner, E. Bischoff, K. D. Bremm, M. Schramm, K. Henninger, R. Kaufmann, H. P. M. Gollnick, C. M. Parker, W. H. Boehncke, Nat. Med. 2002, 8, 366.

[32] A. von Bonin, B. Buchmann, B. Bader, A. Rausch, K. Venstrom, M. Schafer, S. Grundemann, J. Gunther, L. Zorn, R. Nubbemeyer, K. Asadullah, T. M. Zollner, Nat. Med. 2006, 12, 873; B. G. Wienrich, G. J. Oostingh, R. J. Ludwig, S. Enders, G. Harms, R. Tauber, T. Krahn, B. Kramer, W. H. Boehncke, M. P. Schön, Nat. Med. 2006, 12, 873.

[33] M. S. Mulligan, R. L. Warner, J. B. Lowe, P. L. Smith, Y. Suzuki, M. Miyasaka, S. Yamaguchi, Y. Ohta, Y. Tsukada, M. Kiso, A. Hasegawa, P. A. Ward, Int. Immunol. 1998, 10, 569.

[34] M.P.Skinner,D.J.Fournier, R.K.Andrews, J J.Gorman, C. N. Chesterman, M. C. Berndt, Biochem. Biophys. Res. Commun. 1989, 164, 1373.

[35] R. Malhotra, R. Priest, M. R. Foster, M. I. Bird, Eur. J. Immunol. 1998, 28, 983.

[36] M. P. Skinner, C. M. Lucas, G. F. Burns, C. N Chesterman, M. C. Berndt, J. Biol. Chem. 1991 266, 5371.

[37] H. Kawashima, M. Hirose, J. Hirose, D. Nagakubo, A. H. K. Plaas, M. Miyasaka, J. Biol. Chem. 2000, 275, 35448.

[38] H. Kawashima, K. Atarashi, M. Hirose, J. Hirose, S. Yamada, K. Sugahara, M. Miyasaka, J. Biol. Chem. 2002, 277, 12921.

[39] M. Matsuda, K. Shikata, F. Shimizu, Y. Suzuki, M. Miyasaka, H. Kawachi, H. Kawashima, J. Wada, H. Sugimoto, Y. Shikata, D. Ogawa, S.
J. Tojo, K. Akima, H. Makino, J. Pathol. 2002 , 198, 407.

[40] D. Asa, T. Gant, Y. Oda, B. K. Brandley, Glycobiology 1992, 2, 395.

[41] R. J. Ludwig, M. P. Schön, W. H. Boehncke, Expert Opin. Ther. Targets 2007, 11, 1103.

[42] R. J. Ludwig, S. Alban, R. Bistrian, W. H. Boehncke, R. Kaufmann, R. Henschler, J. Gille, Thromb. Haemost. 2006, 95, 535.

[43] J. Dernedde, A. Rausch, M. Weinhart, S. Enders, R. Tauber, K. Licha, M. Schirner, U. Zugel, A. von Bonin, R. Haag, Proc. Natl. Acad. Sci. USA 2010, 107, 19679.

[44] J. Dernedde, S. Enders, H. Reissig, M. Roskamp, S. Schlecht, S. Yekta, Chem. Commun. 2009, 932.

[45] V. R. Krishnamurthy, A. Dougherty, M. Kamat, X. Z. Song, R. D. Cummings, E. L. Chaikof, Carbohydr. Res. 2010, 345, 1541; Y. Vohra, T. Buskas, G. J. Boons, J. Org. Chem. 2009 , 74, 6064; K. Baumann, D. Kowalczyk, T. Gutjahr, M. Pieczyk, C. Jones, M. K. Wild, D. Vestweber, H. Kunz, Angew. Chem. Int. Ed. 2009, 48, 1; K. Baumann, D. Kowalczyk, H. Kunz, Angew. Chem. Int. Ed. 2008, 47, 3445; K. T. Huang, B. C. Wu, C. C. Lin, S. C. Luo, C. P. Chen, C. H. Wong, Carbohydr. Res. 2006 , 341, 2151; K. M. Koeller, M. E. B. Smith, C. H. Wong, J. Am. Chem. Soc. 2000, 122, 742; N. Otsubo, H. Ishida, M. Kiso, Tetrahedron Lett. 2000, 41, 3879.

[46] A. Leppanen, P. Mehta, Y. B. Ouyang, T. Z Ju, J. Helin, K. L. Moore, I. van Die, W. M. Canfield, R. P. McEver, R. D. Cummings, $J$. Biol. Chem. 1999, 274, 24838.

[47] T. V. Pochechueva, O. E. Galanina, M. I. Bird, N. E. Nifantiev, N. V. Bovin, Chem. Biol. 2002, 9, 757 .

[48] A. E. John, N. W. Lukacs, A. A. Berlin, A. Palecanda, R. F. Bargatze, L. M. Stoolman, J. O. Nagy, FASEB 2003, 17, 2296. 